\title{
LOS ASPECTOS DEL RITMO CLIMÁTICO TROPICAL DE LA CIUDAD DE NATAL, BRASIL
}

\author{
Malco Jeiel de Oliveira Alexandre \\ Instituto Federal do Rio Grande do Norte \\ mjoaalexandre@gmail.com \\ DOI: 10.15628/geoconexoes.2018.8053
}

\section{RESUMEN:}

En este estudio se describen las principales características del ritmo climático tropical de la ciudad de Natal, Brasil, a través del análisis de los dados del marco climático. En el proceso de análisis fueron utilizados los datos de las Normales Climatológicas y sinópticos regionales con la finalidad de caracterizar, en líneas generales, los aspectos climáticos locales. En estos datos, se describen los elementos termopluviométricos de la ciudad, las principales condiciones meteorológicas y situaciones sinópticas que actúan en el clima regional. Los resultados permitieron verificar, las características de los cambios ocurridos en las últimas décadas y los principales rasgos del ritmo climático regional y de la ciudad de Natal.

PALABRAS CLAVES: ritmo climático, normales climatológicas, ciudad de Natal.

\section{THE ASPECTS OF THE TROPICAL CLIMATE RHYTHM OF THE CITY OF NATAL, BRAZIL}

\begin{abstract}
:
This study describes the main characteristics of the tropical climate rhythm of the city of Natal, Brazil, through the analysis of the data from the climate framework. In the analysis process, the data of the Climatological Norms and regional synoptics were used with the purpose of characterizing, in general lines, the local climatic aspects. In these data, the thermopluviometric elements of the city, the main meteorological conditions and synoptic situations acting in the regional climate are described. The results allowed to verify, the characteristics of the changes occurred in the last decades and the main features of the regional climate rhythm and the city of Natal.
\end{abstract}

KEY WORDS: climatic rhythm, climatological normals, city of Natal.

\section{INTRODUCCIÓN}

El conocimiento de los aspectos climáticos de una ciudad constituye una fuente importante de información para la comprensión de grande parte de los fenómenos del cuadro ambiental. Por una parte, permite la identificación de las características del clima local con diferentes actuaciones de la 
circulación atmosférica y elementos locales. Por otro lado, el clima influye en las condiciones locales, en especial en las características térmicas y pluviométricas.

En este trabajo abordamos las principales características de la ciudad de Natal a través de los análisis del marco climático. En el proceso de análisis del marco climático se describen las principales condiciones meteorológicas y situaciones sinópticas que actúan en el clima de la región donde si encuentra la ciudad de Natal.

Sin embargo, cualquier intento de estudio de clima hay que emplear la información y los datos históricos. Los estudios históricos de carácter cuantitativo y cualitativo son condiciones sine qua non para el entendimiento de las condiciones atmosféricas. Por lo tanto, para este intento de comprender los aspectos del clima regional y de la ciudad de Natal, los datos de las Normales Climatológicas y de las condiciones sinópticas son fundamentales para cualquier conclusión en relación al clima local (Henderson-Sellers; Mcguffie, 1990).

Los datos fueron obtenidos en los sitios del Instituto Nacional de Meteorología de Brasil (INMET), del Centro de Previsión del Tiempo y Estudios Climáticos de Brasil (CPTEC), del Instituto Brasileño de Geografía y Estadística (IBGE) y los órganos públicos del Estado de Rio Grande del Norte. De hecho, se utilizó los datos bibliográficos de las Normales Climatológicas de los períodos de 1931-1960 y 19611990 además de imágenes del año de 2013, con la finalidad de caracterizar en líneas generales los aspectos del marco climático de la ciudad de Natal.

Los resultados permitieron verificar las principales características de los posibles cambios ocurridos en las últimas décadas y los principales rasgos climáticos regional y local de la ciudad de Natal.

\section{CARACTERÍSTICAS CLIMÁTICAS GENERALES}

La ciudad de Natal es la capital del estado del Rio Grande del Norte, ubicada en el Noreste de Brasil con coordenadas centrales de $5^{\circ} 47^{\prime} 42^{\prime \prime}(\mathrm{S})$ y $35^{\circ} 12^{\prime} 34^{\prime \prime}(0)$, con un área de aproximadamente de 168,53 km2 y población estimada de 870 mil habitantes. (Alexandre, 2013).

El clima de la ciudad de Natal está dentro de la Zona Climática Tropical, donde predominan los climas calientes y húmedos. De manera general, la clasificación climática de un determinado lugar puede ser adoptada en diversos modelos. Para la zona de Natal, se lo hará en los distintos modelos climáticos empíricos de Köppen, Miller, Thornthwaite y Strahler y la clasificación del IBGE.

De acuerdo con la clasificación de Köppen es de tipo "As" esto es, Clima Tropical Lluvioso con estación seca en el verano y de lluvias en el invierno, se puede ver la ciudad de Natal, en el mapa, en detalle en un círculo rojo (Figura 1). En la clasificación de Miller es "A2m" es decir, Clima Caliente Marítimo Tropical del tipo monzón. Y en la clasificación de Thornthwaite de "B4sA'b'4" que indica un Clima Húmedo, con variación de humedad de moderada deficiencia en el verano, megatérmica o cálida. En la clasificación de Strahler es de tipo "Clima de las Latitudes Bajas" (controlados por las masas de aire ecuatorial y tropical) y subdividido en Litoral con los vientos alisios (Jimeno, 2011; Cuadrat, 2011). 


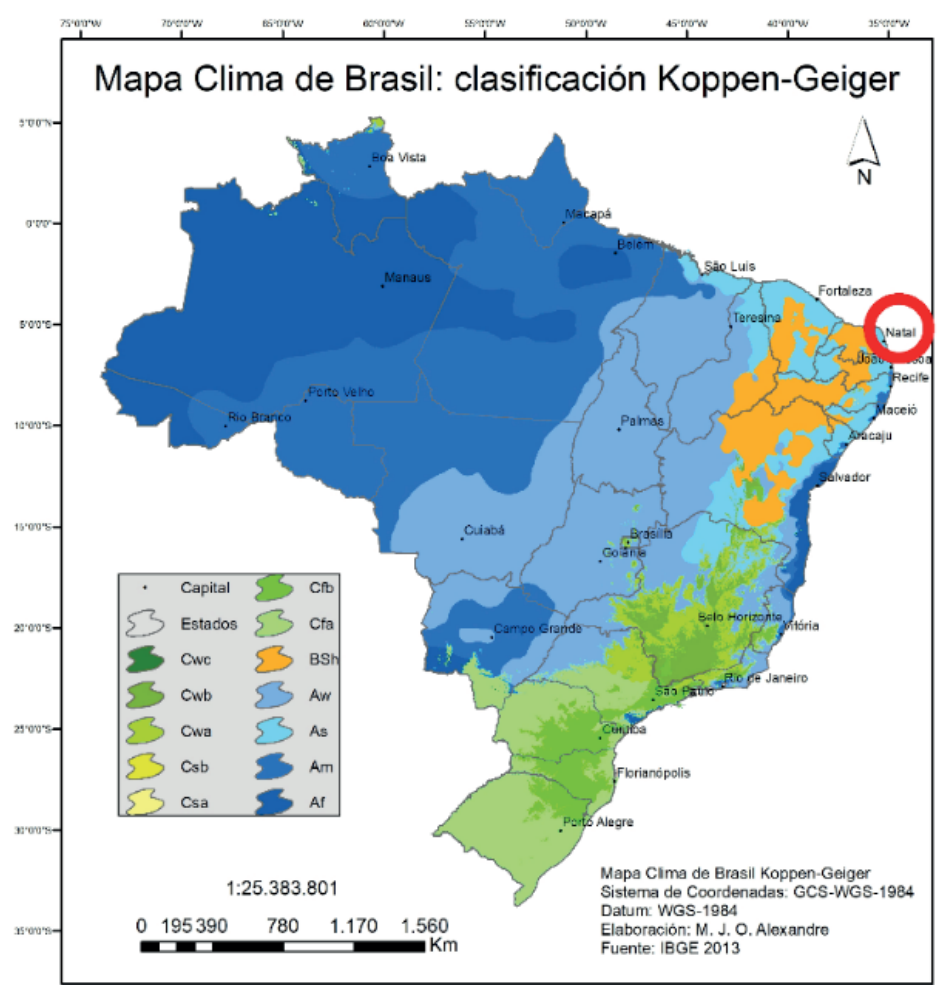

Figura 1 - Mapa climático de Brasil, clasificación Koppen-Geiger. Fuente: IBGE 2013.

La clasificación climática del Instituto Brasileño de Geografía y Estadística (IBGE) se presenta, con datos con detalles en la conjunción de los aspectos físicos, dinámicos y atmosféricos y en gran parte debido a su considerable extensión territorial el "continente Brasil" tiene una gran variedad de tipos de climas.

El IBGE clasifica los climas zonales o genéricos de Brasil en tres grandes grupos Tropical, Ecuatorial y Templado, se puede ver la ciudad de Natal, en el mapa, en detalle en un círculo rojo (Figura 2). En tipo térmicos el clima del país se subdivide en Caliente, Subcaliente, Mesotérmico Suave y Mesotérmico Mediano. La clasificación relacionada con la división regional de la humedad en Súper Húmedo, Húmedo, Semihúmedo y Semiárido (Nimer, 1979). 


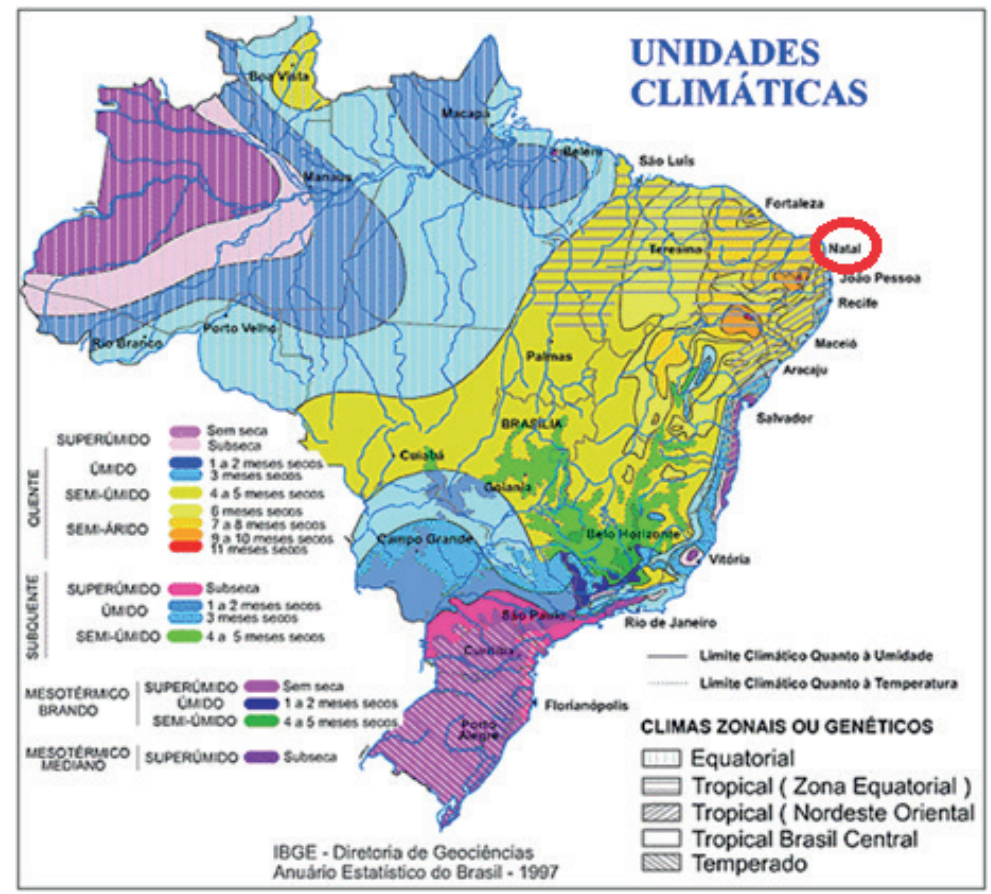

Figura 2 - Mapa de las unidades climáticas de Brasil. Fuente: IBGE.

Así de acuerdo con la clasificación del IBGE la ciudad de Natal queda incluida en el tipo de clima zonal como Clima Tropical Nordeste Oriental, en subtipo térmico como de tipo Caliente, donde la temperatura media en todos los meses del año es mayor que $18^{\circ} \mathrm{C}$ y en con relación a la subdivisión de humedad en tipo Semihúmedo de 4 a 5 meses secos.

\section{LOS SISTEMAS SINÓPTICOS}

Las situaciones sinópticas más frecuentes que afectan el clima de la ciudad de Natal, están a menudo, muy asociadas, al desplazamiento de la Zona de Convergencia Intertropical (ZCIT), del Disturbio Ondulatorio del Este (DOL), Vórtices Ciclónicos en Altos Niveles (VCAN), de los Sistemas Frontales y de los vientos alisios de sureste procedentes del océano Atlántico Sur. La actuación de estos sistemas atmosféricos de gran magnitud tiene repercusión muy importante en la climatología local principalmente en relación a las precipitaciones (Molion, 2002; Cavalcanti, 2009; Mendonça, 2007).

La Zona de Convergencia Intertropical (ZCIT), que es una formación latitudinal de nubes debido a los vientos alisios de Noreste y Sureste en la región del Ecuador terrestre, con variación aproximada de $14^{\circ} \mathrm{N}$ hasta $5^{\circ} \mathrm{S}$. La ZCIT afecta directamente a las precipitaciones en el sector Noreste Oriental de la región Noreste de Brasil (NEB) donde se encuentra Natal (Ayoade, 2003; Mendonça, 2007).

El Disturbio Ondulatorio del Este (DOL) actúa en el Atlántico Sur entre $20^{\circ} \mathrm{N}$ y $20^{\circ} \mathrm{S}$ y con dirección al Noreste de Brasil, como se observa en el conjunto muy visible de nubosidad el Noreste de Brasil (Figura 3). Tiene un padrón de nubosidad y líneas de instabilidad muy frecuentes en el período de invierno o de Iluvias en la costa Este del NEB (Cavalcanti, et al, 2009).

El Vórtices Ciclónicos en Altos Niveles (VCAN), son de origen tropical, actúan con frecuencia en el NEB. Tiene una formación con la siguiente característica, en el centro del vórtice presenta un tiempo 
abierto sin lluvias y en la periferia presenta lluvias muy intensas. Su presencia es muy frecuente en la región NEB, en los meses de diciembre a febrero (Cavalcanti, et al, 2009).

Los sistemas frontales actúan principalmente entre mayo a agosto entre las latitudes de $5^{\circ} \mathrm{S}$ a $18^{\circ} \mathrm{S}$ y son responsables por intensas precipitaciones en la franja Oriental del estado del Rio Grande do Norte, donde se encuentra Natal (Cavalcanti, et al, 2009; Araujo, 2010).

Otro fenómeno de gran influencia en el clima regional es El Niño Oscilación del Sur (ENOS) que tiene como principal característica el calentamiento anormal de las aguas del Océano Pacífico Sur. Una de las principales influencias del El Niño en el Noreste de Brasil son las sequías de diferentes intensidades y su opuesto es La niña o el Anti El Niño que trae las condiciones normales de precipitaciones para la región (Mendonça, 2007, Vianello, 2013).

Las situaciones sinópticas típicas de invierno están en la Figura 3. El Anticiclón Subtropical del Atlántico Sur (ASAS) o Anticiclón de Santa Helena, con centro de alta presión en torno de $30^{\circ} \mathrm{S}$ del Atlántico Sur influye en el clima de gran parte de Brasil, favoreciendo el transporte de humedad desde el océano a la costa. Esto sistema afecta el Noreste de Brasil, actúa con tiempo perturbado a través de la circulación de los vientos del Este/Sureste y de Disturbios Ondulatorios del Este (DOL o EW) que añaden humedad desde el océano formando precipitaciones variadas o significativas en la costa oriental del Estado del RN donde se localiza la ciudad de Natal. En relación a la Zona de Convergencia Intertropical (ZCIT) oscila alrededor de $6^{\circ} \mathrm{N}$ a $10^{\circ} \mathrm{N}$ en el Atlántico, tiene una influencia reducida o poca influencia en la región. (CPTEC/INPE, 2013).

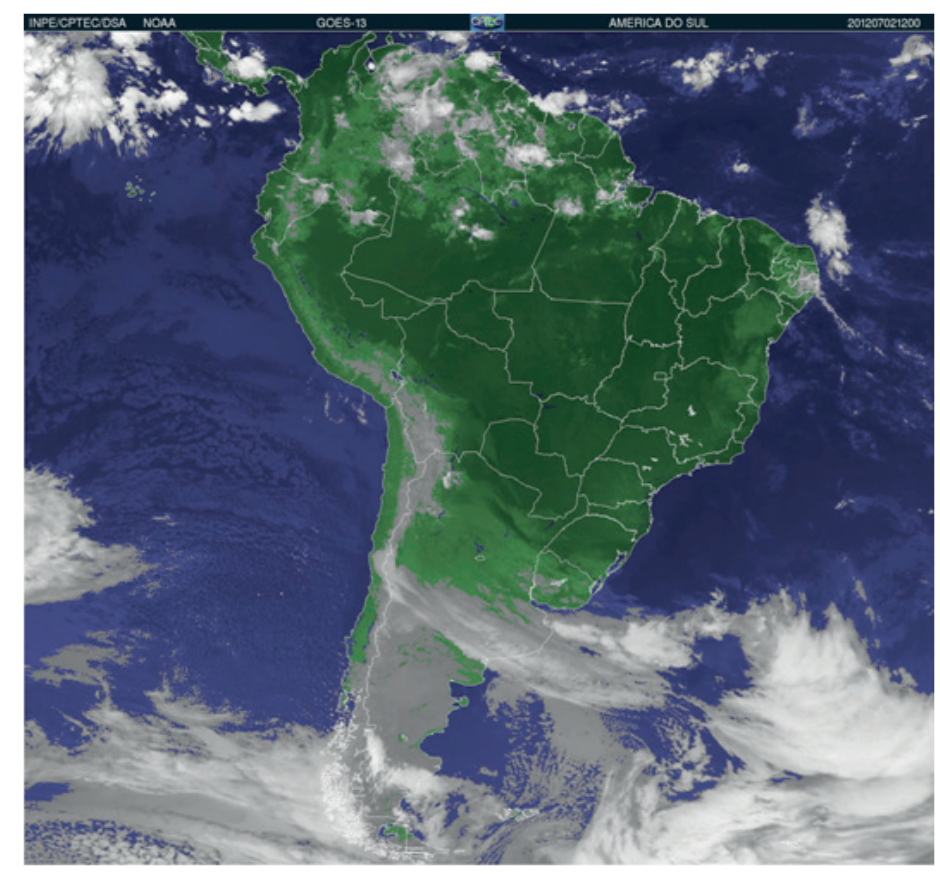

Figura 3 - Mapa de la América del Sur con la imagen del satélite GOES en el mes de julio período de invierno. Fuente: CPTEC, INPE, 2013.

Las situaciones sinópticas típicas de primavera están en la Figura 4. El Anticiclón Subtropical del Atlántico Sur (ASAS), influye en el clima de gran parte de Brasil, contribuye con advección del aire 


\section{ISSN - 2359-6007}

marítimo sobre la costa Este de Brasil a través de los vientos de Este/Sureste, pero con baja probabilidad de lluvia. En el Noreste de Brasil el período de sequía en la región donde se encuentra la ciudad de Natal, la actuación del ASAS es inexistente (CPTEC/INPE, 2013).



Figura 4 - Mapa de la América del Sur con la imagen del satélite GOES en el mes de octubre período de primavera. Fuente:

CPTEC, INPE, 2013.

Las situaciones sinópticas típicas de verano están en la Figura 5. La Zona de Convergencia Intertropical (ZCIT) oscila en el Ecuador alrededor de $3^{\circ} \mathrm{N}$ a $4^{\circ} \mathrm{S}$ en el Atlántico, tiene una influencia muy determinante en la región septentrional de Brasil asociada al tiempo perturbado con muchas e intensas precipitaciones en estos sectores. En el Noreste de Brasil el hecho sinóptico principal son los vientos de Noreste los que predominan con flujo medio y esta condición provoca tiempo más seco con pocas nubes y cielos despejados en el sector de la costa Este del Nordeste de Brasil (en la región de Natal). Otro hecho sinóptico es el Vórtice Ciclónico de Altos Niveles (VCAN) que actúa sobre el Noreste brasileño en proceso de subsidencia de zonas de alta presión con pocas nubes y cielos despejados (CPTEC/INPE, 2013). 


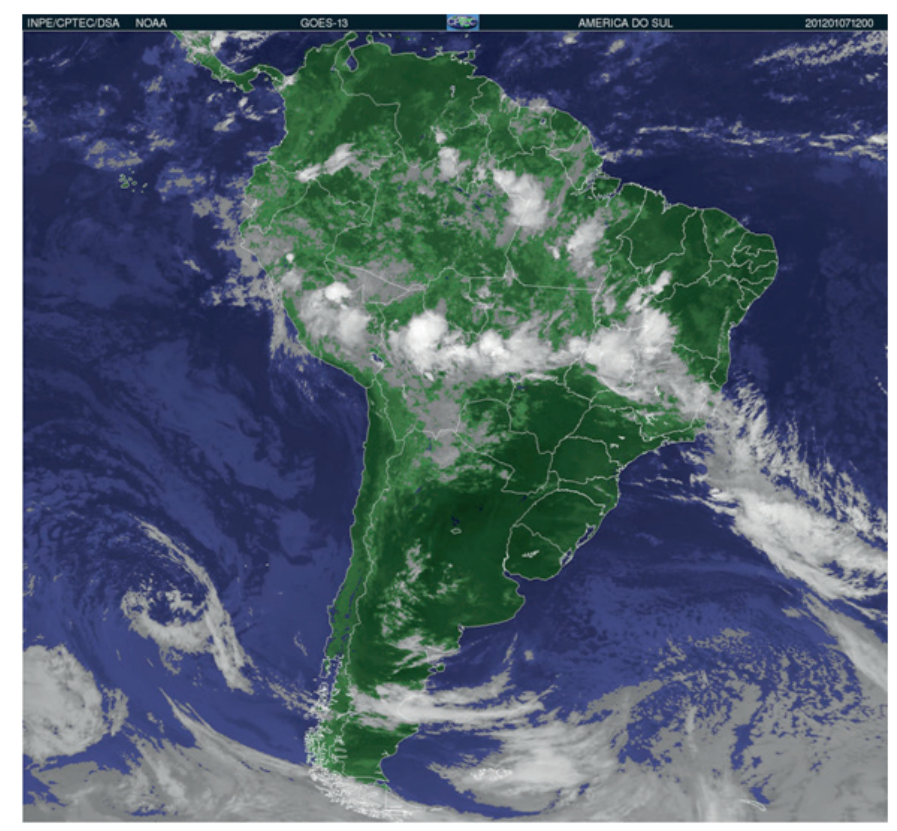

Figura 5 - Mapa de la América del Sur con la imagen del satélite GOES en el mes de enero período de verano. Fuente: CPTEC, INPE, 2013.

Las situaciones sinópticas típicas de otoño está en la Figura 6. La Zona de Convergencia Intertropical (ZCIT) está posicionada por encima del Ecuador alrededor de $2^{\circ} \mathrm{N}$ a $5^{\circ} \mathrm{N}$ en el Atlántico y tiene su influencia disminuida en la región Noreste de Brasil. El hecho sinóptico principal es la actuación del Anticiclón Subtropical del Atlántico Sur (ASAS) con los vientos de Este que añaden humedad del océano para el continente y favorece la formación de nubes en el caso el sector este del país (CPTEC/ INPE, 2013). 


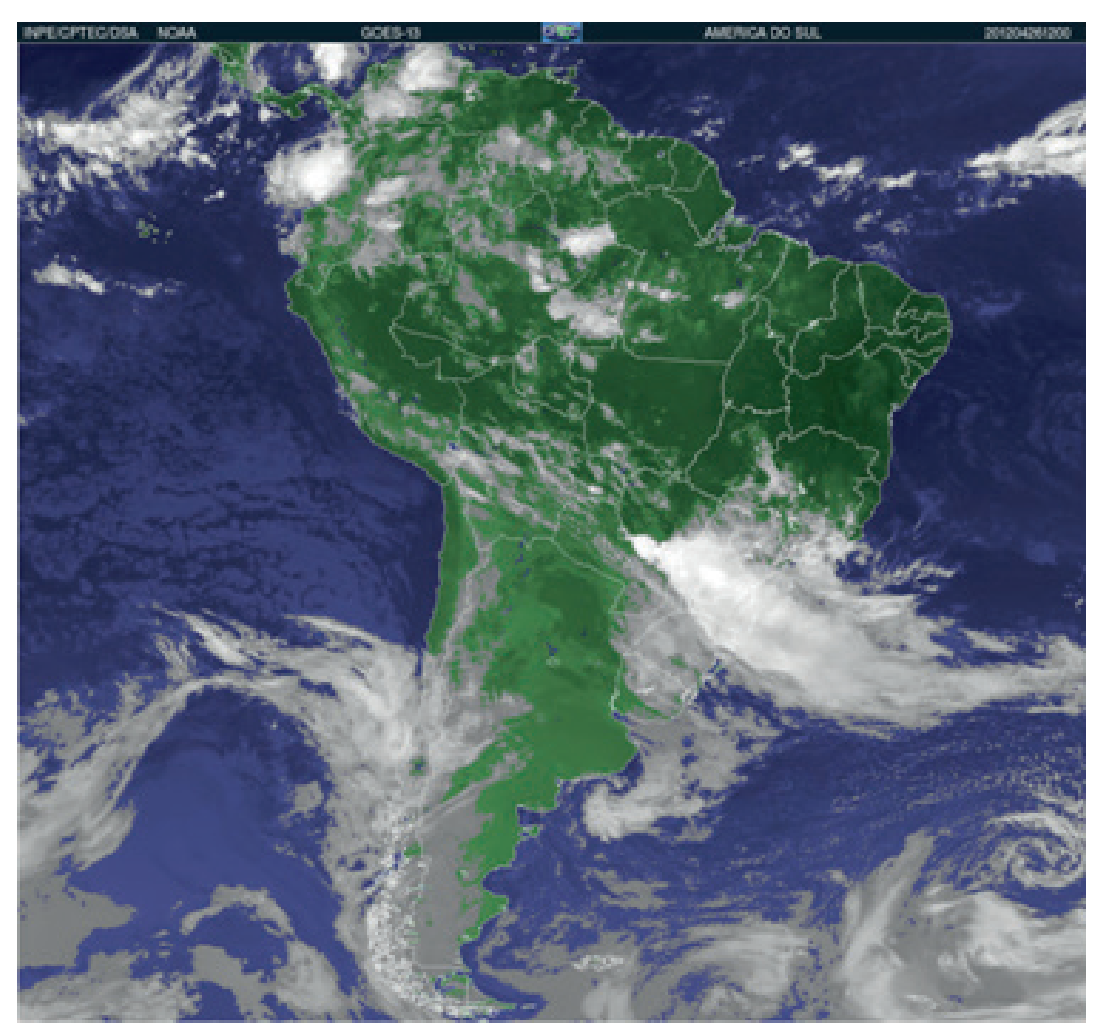

Figura 6 - Mapa de la América del Sur con la imagen del satélite GOES en el mes de abril período de otoño. Fuente: CPTEC, INPE, 2013

La dinámica atmosférica de los principales Sistemas Sinópticos que actúan en el Noreste de Brasil y en consecuencia en la región de la ciudad de Natal, teniendo en cuenta las diferentes intensidades temporales y espaciales y su influencia en las precipitaciones son (Tabla 1): la Zona de Convergencia Intertropical (ZCIT), los Disturbios Ondulatorios del Este (DOL o EW), el Vórtices Ciclónicos en Altos Niveles o del Aire Superior (VCAN o VCAS), las Líneas de Inestabilidad Tropical en el litoral (LI o IT), los vientos Alisios de Sureste (AS) del Anticiclón Subtropical del Atlántico Sur (ASAS), periódicamente la presencia y actuación de El Niño Oscilación del Sur (ENOS), en menor escala los Complejos Convectivos de Mesoescala (CCM).

Tabla 1 - Las situaciones sinópticas más frecuentes en Natal (NEB).

\begin{tabular}{l|l|l|l|l|l|l|l|l|l|l|l}
\hline ENE & FEB & MAR & ABR & MAY & JUN & JUL & AGO & SEP & OCT & NOV & DIC \\
\hline VCAN & $\begin{array}{l}\text { ZCIT } \\
\text { VCAN }\end{array}$ & $\begin{array}{l}\text { ZCIT } \\
\text { VCAN }\end{array}$ & $\begin{array}{l}\text { ZCIT } \\
\text { VCAN } \\
\text { LI }\end{array}$ & $\begin{array}{l}\text { DOL } \\
\text { LI } \\
\text { AS }\end{array}$ & $\begin{array}{l}\text { DOL } \\
\text { LI } \\
\text { AS }\end{array}$ & $\begin{array}{l}\text { DOL } \\
\text { LI } \\
\text { AS }\end{array}$ & $\begin{array}{l}\text { DOL } \\
\text { LI } \\
\text { AS }\end{array}$ & $\begin{array}{l}\text { LI } \\
\text { AS }\end{array}$ & & & \\
\hline
\end{tabular}

Fuente: CPTEC, INMET, 2013. 


\section{LOS ELEMENTOS DEL CLIMA LOCAL}

La ciudad de Natal presenta dos estaciones distintas, el período de las lluvias o el período de otoño e invierno (abril, mayo, junio y julio) y el período de sequía o primavera y verano (octubre, noviembre, diciembre y enero). Así, el tipo de condiciones climáticas dominante en la ciudad de Natal es tropical caliente húmedo con los veranos secos y el invierno húmedo, incluyendo toda la extensión de la costa Este del estado del Estado del Rio Grande do Norte. Debido a sus características tropicales las estaciones climáticas en Natal están condicionadas por las lluvias (Alexandre, 2013; Ayoade, 2003).

La ciudad de Natal a partir de los datos de las Normales Climatológicas de 1931-1960, las temperaturas máximas oscilan entre $27,7^{\circ} \mathrm{C}$ a $30,3^{\circ} \mathrm{C}$ y las mínimas entre $20,3^{\circ} \mathrm{C}$ a $24,3^{\circ} \mathrm{C}$ (Figura 7 ). El régimen pluviométrico presenta un total anual de $1.542,6 \mathrm{~mm} / \mathrm{año}$, más del $70 \%$ se concentran en el otoño e invierno (Normales Climatológicas, INMET, 2013).

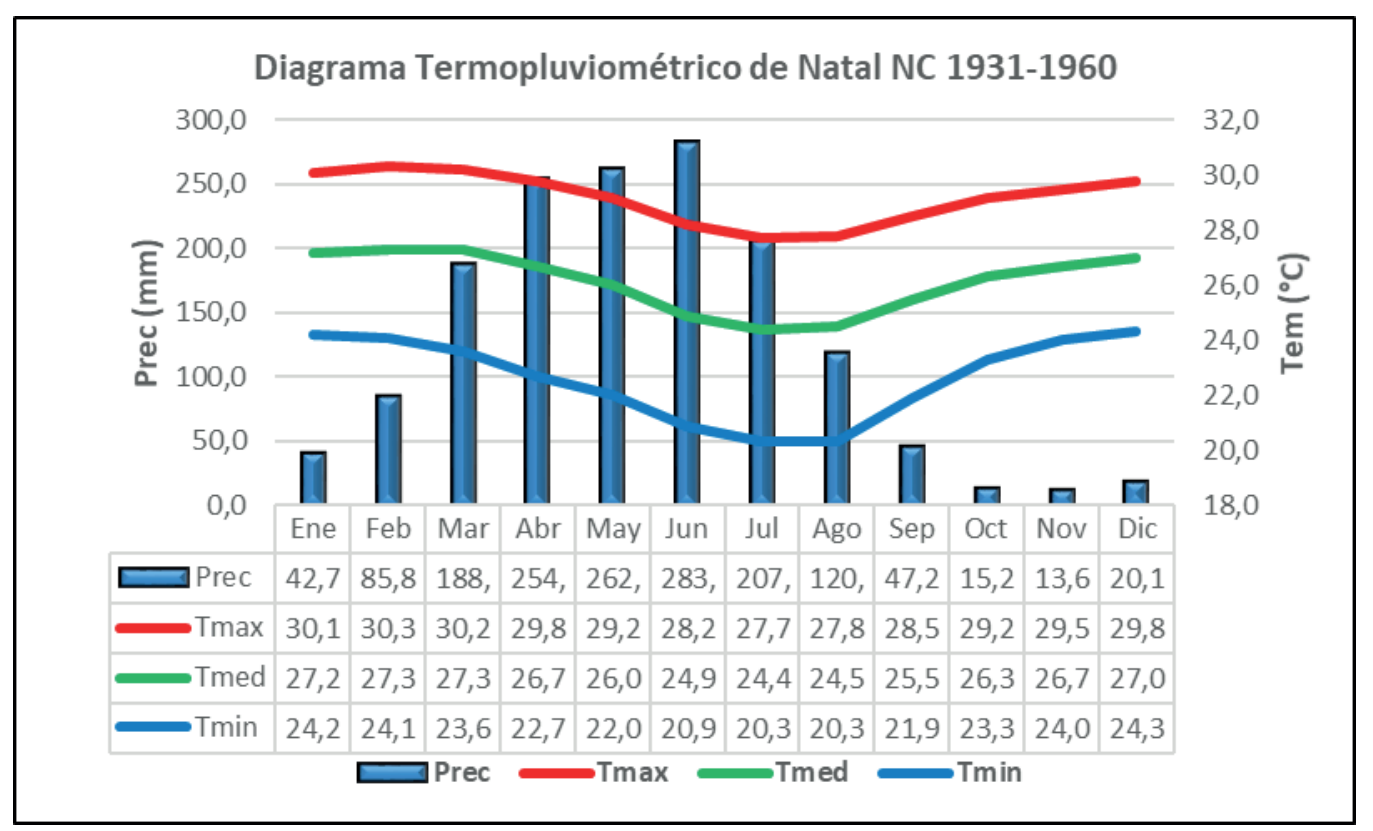

Figura 7 - Diagrama Termopluviométrico de Natal 1931-1960. Fuente: Normales Climatológicas 1931-1960, INMET

En las Normales Climatológicas de 1961-1990, las temperaturas máximas oscilan entre $27,7^{\circ} \mathrm{C}$ a $30,5^{\circ} \mathrm{C}$ y las mínimas entre $20,7^{\circ} \mathrm{C}$ a $24^{\circ} \mathrm{C}$ (Figura 8). El régimen pluviométrico presenta un total anual de $1.465,4 \mathrm{~mm} / \mathrm{año}$, más del $70 \%$ se concentran en el otoño e invierno (Normales Climatológicas, INMET, 2013). 


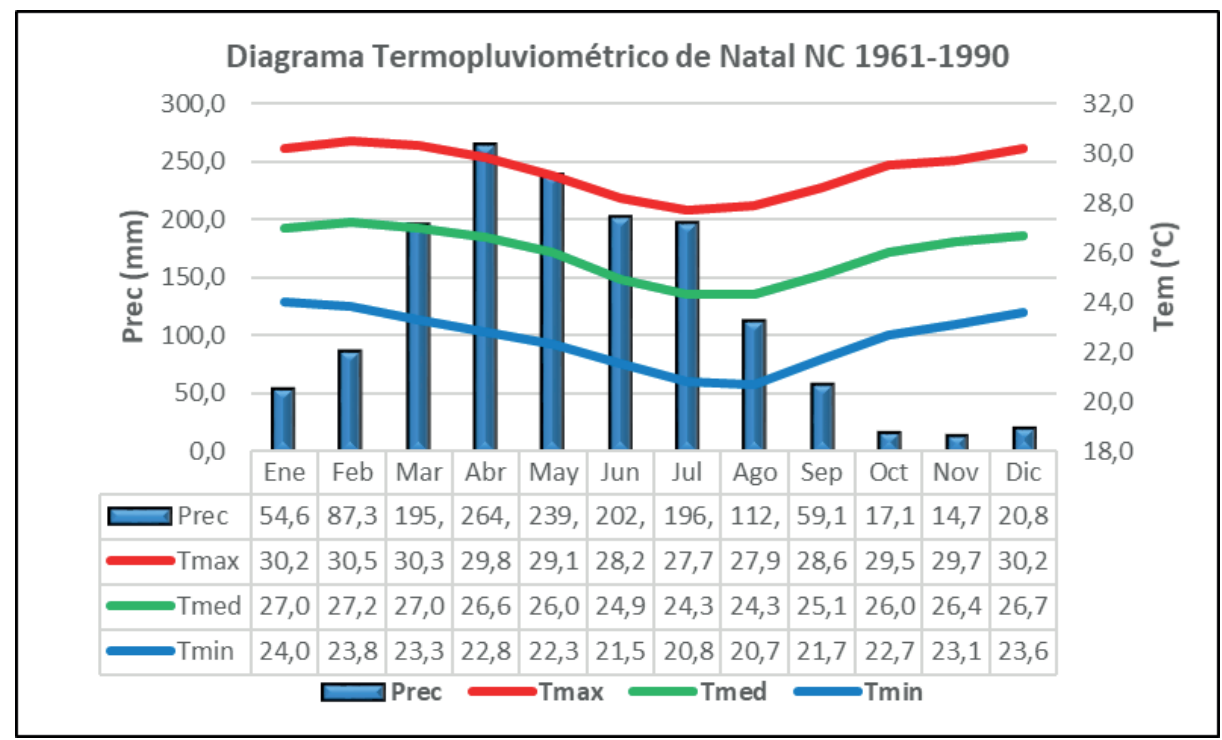

Figura 8 - Diagrama Termopluviométrico de Natal 1960-1990. Fuente: Normales Climatológicas 1961-1990, INMET.

El Estado del Rio Grande del Norte, donde está la ciudad de Natal tiene una irregular distribución espacial y temporal de lluvias. El mapa de la pluviometría del Estado (Figura 9) se observa un mayor volumen de precipitación en la franja oriental del Estado y en el centro y oeste con menores volúmenes. Los máximos en el otoño e inverno y mínimos en primavera y verano. Así, en la ciudad de Natal, el final del otoño y el invierno es la estación de las lluvias donde hay un superávit de $1.040 \mathrm{~mm}$ de agua que se distribuye entre febrero y agosto, con una humedad relativa promedio de $77 \%$ y temperatura anual media de la ciudad de $26,7^{\circ} \mathrm{C}$ (Normales Climatológicas, INMET, 2013).

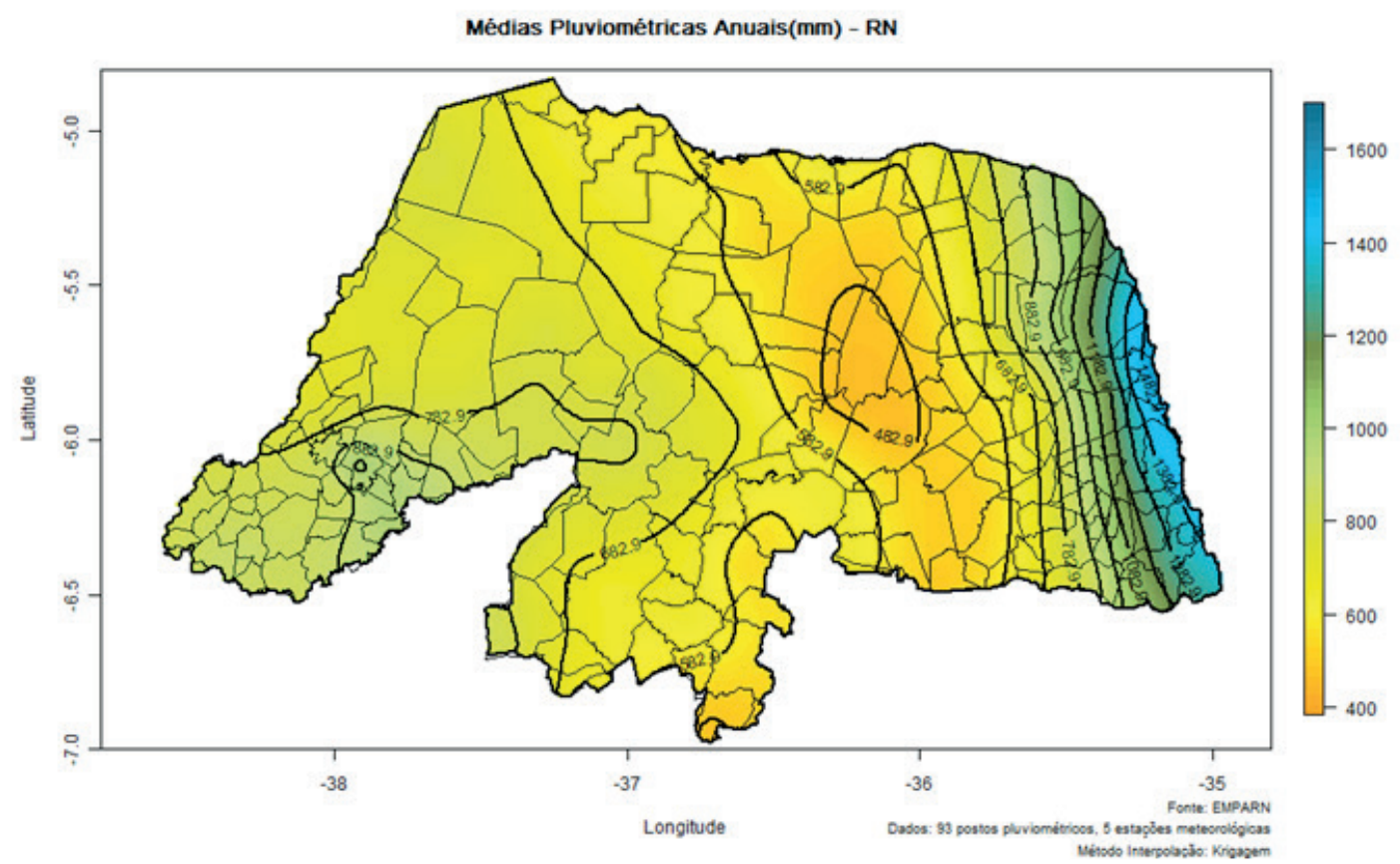

Figura 9 - Mapa de la pluviometría del Estado del Rio Grande do Norte, promedio anual. Fuente: EMPARN, 2013. 
El régimen de vientos predominantes para la ciudad está representado en la Figura 10 y se observa que en más del $90 \%$ de los casos para todo el año la dirección predominante es de SE-S Sureste-Sur. La velocidad media del viento oscila en un rango entre $3,6 \mathrm{~m} / \mathrm{s}$ y $5,7 \mathrm{~m} / \mathrm{s}$ clasificado entre vientos flojos a moderados en la escala Beaufort. La ciudad presenta una regularidad anual de los vientos con un promedio de velocidad de 4,4m/s. Estos vientos regulares y constantes ayudan a mantener un clima agradable y fresco en la ciudad.

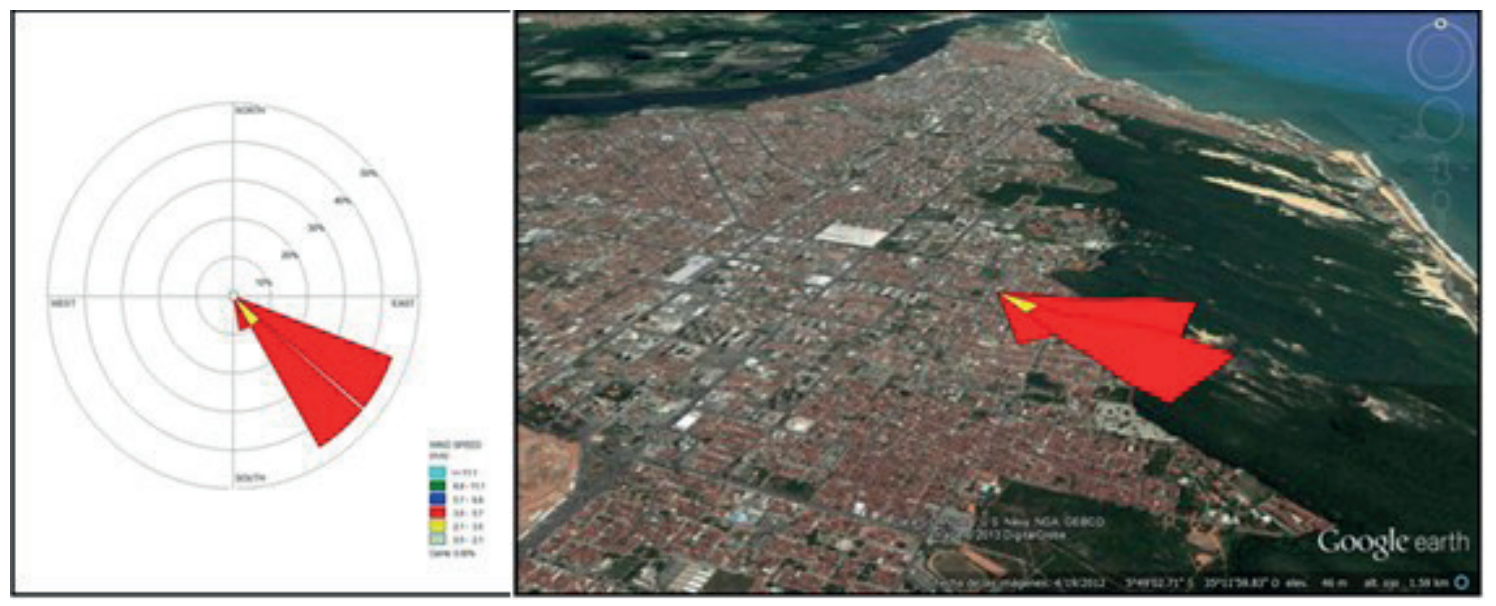

Figura 10 - Dirección predominante de los vientos el Natal. Fuente: Normales Climatológicas 1961-1990, INMET.

Los datos de la precipitación acumulada comparativa de Natal entre los datos de las Normales Climatológicas de 1931-1960 y 1961-1990 están en la Figura 11. Los más significativos cambios, fueron de la cuadra lluviosa. Hay un distinto cambio entre los meses de abril a junio, ascendente en el periodo de 1931-1960 y descendente de 1961-1990. De manera general, los valores del volumen de lluvias entre los meses de abril a julio en los dos períodos, también presentan cambio en las cantidades, siendo: en el período 1931-1960 con el total de 801,1 mm de precipitación y entre 1961-1990 de 706,5mm, siendo la diferencia entre los dos períodos de 94,6mm. De acuerdo con García (1996), hay algunas dificultades para entender los rasgos generales de las precipitaciones, de los cuales, la irregularidad - que es muy acusada en las zonas de transición como en Natal, duración e intensidad - los efectos muy diferentes entre las cantidades del total registrado en los observatorios y las disponibilidades hídricas - muy dependientes de la cantidad precipitada y de la evaporación. Por lo tanto, para una mejor conclusión de esto fenómeno de cambio de cantidades entre la distribución temporal entre los dos períodos, hay que analizar muy a menudo con los datos sinópticos y atmosféricos, que no es el caso para este estudio. 


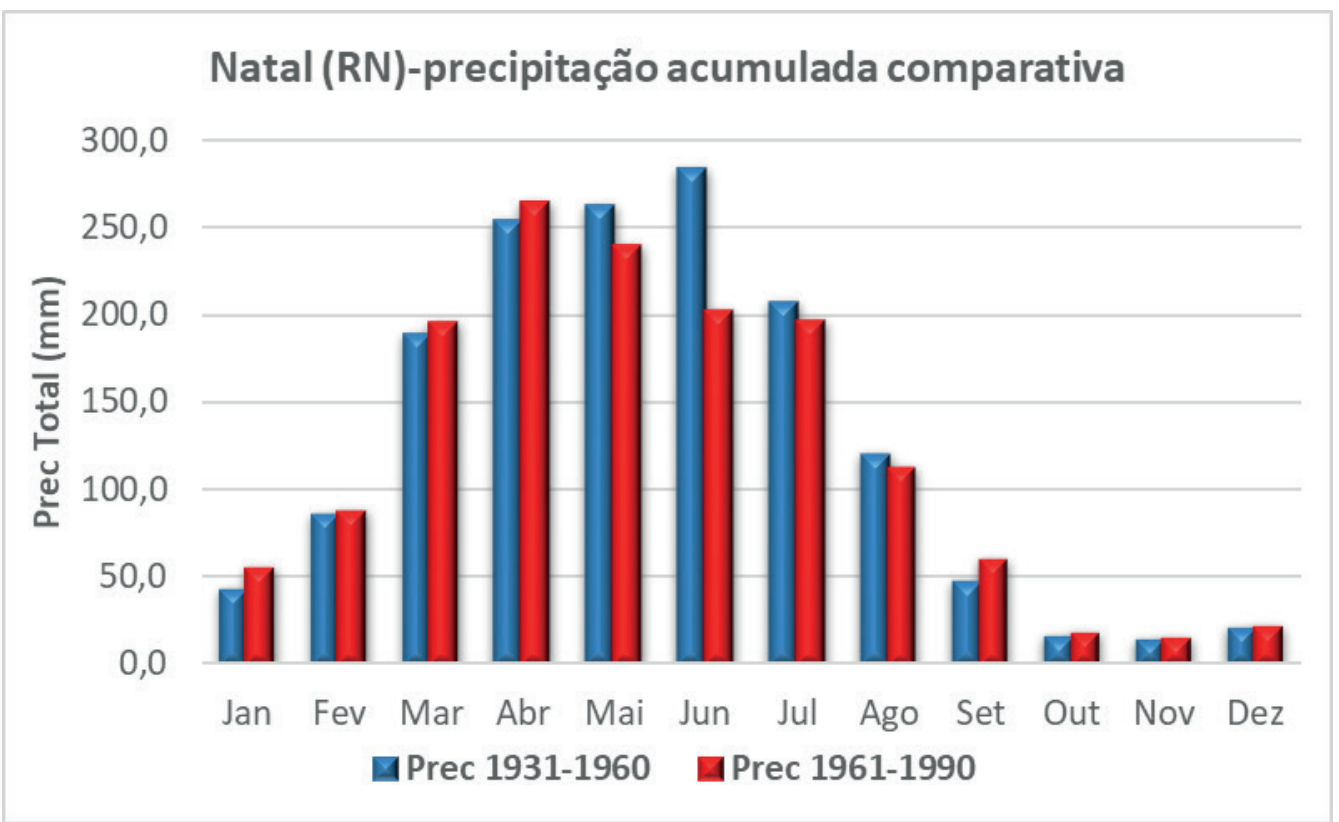

Figura 11 - Los datos de la precipitación acumulada comparativa mensual entre las Normales Climatológicas de 1931-1960 e 1961-1990. Fuente: Normales Climatológicas 1931-1960; 1961-1990, INMET, 2013.

\section{CONCLUSIÓN}

Los aspectos climáticos de la ciudad de Natal están muy asociados a la localización y la dinámica atmosférica que actúan en el Noreste de Brasil.

De hecho, la región Noreste de Brasil, tiene una climatología muy anómala debito a los muy complejos sistemas atmosféricos actuantes además de los cambios muy significativos debito a la presencia irregular del El Niño Oscilación del Sur (ENOS).

Los principales Sistemas Sinópticos que actúan en la región donde está ubicada la ciudad de Natal, teniendo en cuenta las diferentes intensidades temporales y espaciales y su influencia en las precipitaciones son: al desplazamiento de la Zona de Convergencia Intertropical (ZCIT), los Disturbios Ondulatorios del Este (DOL o EW), el Vórtices Ciclónicos en Altos Niveles o del Aire Superior (VCAN o VCAS), las Líneas de Inestabilidad Tropical en el litoral (LI o IT), los vientos Alisios de Sureste (AS) del Anticiclón Subtropical del Atlántico Sur (ASAS), periódicamente la presencia y actuación de El Niño Oscilación del Sur (ENOS)

La ciudad de Natal, los datos demuestran, que presenta dos estaciones bien características y distintas, el período lluvioso o el período de otoño e invierno (abril, mayo, junio y julio) y el período de sequía o primavera y verano (octubre, noviembre, diciembre y enero), con una regular distribución de los volúmenes de precipitaciones.

\section{BIBLIOGRAFÍA}

1. ALEXANDRE et al. Las oscilaciones climáticas en la atmosfera urbana de la ciudad de Natal, Brasil através de las series largas de temperaturas del aire. Natal: Holos, 2013, ano 29, v.5, p 137-156. 
2. ARAÚJO NEVES, J. et al (2010). Análise Pluviométrica do Rio Grande do Norte: Período: 19632009. Natal: EMPARN, p 71.

3. AYOADE, J. O. (2003). Introdução à climatologia para os trópicos. 9 ed. Rio de Janeiro, Bertrand Brasil.

4. CAVALCANTI, Iracema F. de A. et al (orgs). Tempo e clima no Brasil. São Paulo: Oficina de textos, 2009.

5. Centro de Previsão do Tempo e Estudos Climáticos. Instituto Nacional de Pesquisas Espaciais. Boletín Técnico 2011, 2012 y 2013. Disponible en: http://tempo.cptec.inpe.br/bol_tecnico.shtm. Asesado en marzo de 2013.

6. CUADRAT, José M.; Pita, M. Fernanda. Climatología. 6 ed. Madrid: Ediciones Cátedra, 2011.

7. Instituto Nacional de Meteorologia. Banco de Dados Meteorológicos. Brasília: INMET: 19602013. Disponible en: : http://www.inmet.gov.br. Asesado en marzo de 2013.

8. Empresa de Pesquisa Agropecuária do Rio Grande do Norte. (2013). Dados Meteorología e climatología. Natal: EMPARN. Disponible en: http://www.emparn.rn.gov.br. Asesado en marzo de 2013.

9. GARCÍA, Felipe Fernández. Manual de climatología aplicada: clima, medio ambiente y planificación. Madrid: Editorial Sintesis, 1996.

10. MENDONÇA, F., Danni Oliveira, I. M. (2007). Climatologia: noções básicas e climas do Brasil. São Paulo: Oficina de textos.

11. JIMENO, Manuel Ledesma. Principios de meteorología y climatología. 1 ed. Madrid: 2011.

12. NIMER, E. Um modelo metodológico da classificação de climas. Rio de Janeiro: Instituto Brasileiro de Geografía e Estatística, Revista Brasileira de Geografia, 1979, n. 4, v 41, p. 59-89.

13. INMET Instituto Nacional de Meteorologia. (2013). Normais Climatológicas do Brasil, Períodos 1931-1960 e 1961-1990. Disponible en: http://www.inmet.gov.br. Asesado en marzo de 2013.

14. MOLION, L. C. B., Bernardo, S. de O. (2002). Uma revisão da dinâmica das chuvas no Nordeste brasileiro. Revista Brasileira de Meteorologia, v.17, n.1, pp 1-10.

15. HENDERSON-SELLERS, A.; MCGUFFIE, K. Introducción a los Modelos climáticos. Barcelona: Omega, 1990.

16. VIANELLO, Rubens Leite; ALVES, Adil Rainier. Meteorologia básica e aplicações. Viçosa MG: Universidade Federal de Viçosa, 2013. 